\title{
Familial clustering of multiple sclerosis in a northern Swedish rural district
}

\author{
M Binzer, L Forsgren, G Holmgren, U Drugge, S Fredrikson
}

\begin{abstract}
A small rural district in the most northerly province of Sweden was found to have a very high occurrence of multiple sclerosis. A total of 12 patients with multiple sclerosis among 4744 inhabitants were identified (five females, seven males), corresponding to a prevalence of 253/100 000. Many of the patients were related and a further 21 cases with multiple sclerosis (14 females, seven males), mostly living in the neighbouring area, have family ties to the district. A genealogical investigation showed that 22 of the 33 patients identified had ties of kinship and thus, to our knowledge, the largest aggregation of multiple sclerosis in a family is presented.
\end{abstract}

(F Neurol Neurosurg Psychiatry 1994;57:497-499)

Epidemiological and clinical investigations in multiple sclerosis have found a familial aggregation in up to $20 \%$ of cases. ${ }^{12}$ The higher concordance rates in monozygotic twins than in dizygotic twins provides strong evidence for a genetically controlled susceptibility to multiple sclerosis. ${ }^{34}$

When the prevalence of multiple sclerosis exceeds 60 per 100000 the area is considered to be at high risk, but several countries surveyed show highly significant deviations from homogeneity and the high rate areas tend to be contiguous forming clusters or foci. ${ }^{5}$ There is a 10-fold difference between regions with the lowest and highest occurrence. Also a number of clusters of unrelated persons have been reported and continue to attract attention although they tend to be anecdotal..$^{6-8}$ Clusters of cases in families are a feature of most surveys of multiple sclerosis but many reports $^{9-11}$ appeared before the era of CSF electrophoresis for the demonstration of oligoclonal bands, and MRI techniques. The studies also rarely describe more than a few cases in the same sibship.

In the present study a large number of patients with multiple sclerosis were found to be living or to have family ties in a small northern Swedish rural district. A high proportion of these patients are related to each other and, to our knowledge, the largest aggregation of multiple sclerosis in a family, is presented.

\section{Patients and methods}

The district surveyed is located in the northernmost part of Sweden (fig 1). It has an area of $2791 \mathrm{~km}^{2}$ and the population on 31 December 1990 was 4744 . Most inhabitants live in the small town of Överkalix and the population is ethnically homogeneous.

Local general practitioners had reported a high level of multiple sclerosis in the area and persons with suspected multiple sclerosis in the district were then identified through local physicians and the local multiple sclerosis society.

Multiple sclerosis was defined according to the criteria of Schumacher et al. ${ }^{12}$ Only cases with clinically definite multiple sclerosis were included. Patients were identified as either relapsing/remitting or primary chronic progressive without remission. Fifty two per cent (17/33) of the patients were examined by one of us (MB). The diagnosis of the remaining patients was confirmed by another specialist experienced in diagnosing multiple sclerosis. Degree of disability was assessed according to the Kurtzke disability status scale. ${ }^{13}$

To establish possible kinships in the material an extensive genealogical study was

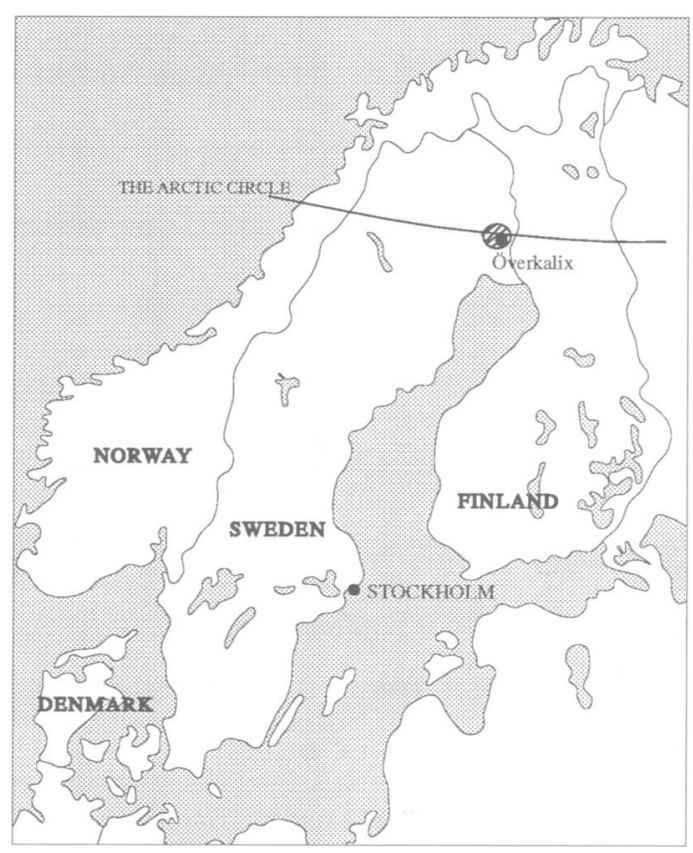

Figure 1 Map of Scandinavia with the investigation area hatched. 
undertaken. Local parish registers were used as well as registers converted into microfiches at the research archives at Umeå University, a data base in which the principal sources constitute parish registration material from the 17 th up to the end of the 19 th century.

The identified cases reported here were either inhabitants of the investigated district on the prevalence day, 31 December 1990, or were patients with multiple sclerosis living elsewhere but with family ties to the investigated district.

\section{Results}

A total of 33 cases (19 females, 14 males) were identified. Only one new patient was diagnosed as a consequence of the study. Twenty two patients were born in the district. The remaining 11 were born in surrounding counties. One of these cases (No 28) had died in 1976 but was included because he was known to be related to at least six other patients. Necropsy examination was not performed on this patient. For all 33 cases, mean age at onset was $29 \cdot 6$ (SD $8 \cdot 1$; range $12-49$ ) years, $30 \cdot 2$ (SD $6 \cdot 7$; range 20-44) for males and $29 \cdot 2$ (SD $9 \cdot 1$; range $12-49$ ) for females. The patients showed the usual pattern of clinical features with most cases (25/33) following a remitting and relapsing course. The mean age of the 32 patients on the prevalence day was $49 \cdot 2$ (SD $10 \cdot 9$; range $23-78$ ) years and the mean duration of disease 19.5 (SD 11.9 ; range $2-59$ ) years. The median disability status scale for the 32 patients examined was $5 \cdot 0$ (SD $2 \cdot 1$; range $2-9$ ). Ninety seven per cent $(32 / 33)$ were examined by isoelectric focusing of CSF and all had oligoclonal bands. Twenty seven per cent $(9 / 33)$ were examined by MRI and all of these had periventricular lesions typical of multiple sclerosis. (Information of individual patients can be obtained on request.)

On the prevalence date 12 of the patients (five females, seven males) were inhabitants of the district; the mean age was 53.5 (SD $11 \cdot 7$; range $36-78$ ) years. This corresponds to a prevalence of $253 / 100000$ (males $285 / 100000$, females $218 / 100000$ ).

Ties of kinship were established in 22 of 33 cases all with common roots to the 18 th century (fig 2). Patient No VII:19 and VII:20 were sisters and patient No IX:14 and VIII:12 second degree relatives, whereas kinship in the remaining patients was distant. All related patients were born in Överkalix, except five who were born in neighbouring counties. Seven of the patients lived in Överkalix, 13 elsewhere in Norrbotten, and two, including the deceased, lived in southern Sweden. Eight patients were males and 14 were females. The mean age of onset for the pedigree was 28.8 (SD $9 \cdot 2$; range $12-49$ ) years. Mean duration of disease at the prevalence day was 19.7 (SD 13.0; range 3-59) and mean disability status scale $5 \cdot 0$ (SD $2 \cdot 0$; range 2-9).

From church archives we tried to identify suspected multiple sclerosis cases in previous generations in our pedigree and searched back to the 18 th century. We were only able to identify three possible candidates, all of whom lived during the 19th century. One of these, V:7, was described as a "cripple". Another, V:26, was described as being "sickly", and the third candidate, VIII:7, had weak vision.

Of the remaining 11 patients not fitting into the pedigree there was one sibling pair. The ancestory of 33 patients was traced back to the middle of the 18th century and common roots were only found for another two patients.

\section{Discussion}

To our knowledge, a pedigree of the size described here has not been presented previously and emphasises the importance of genetic factors in the pathogenesis of multiple sclerosis. The number of patients with multiple sclerosis represented in the pedigree ( 22 out of 33 registered patients in the area) is far bigger than could be expected from any random sample of linkage of common ancestors

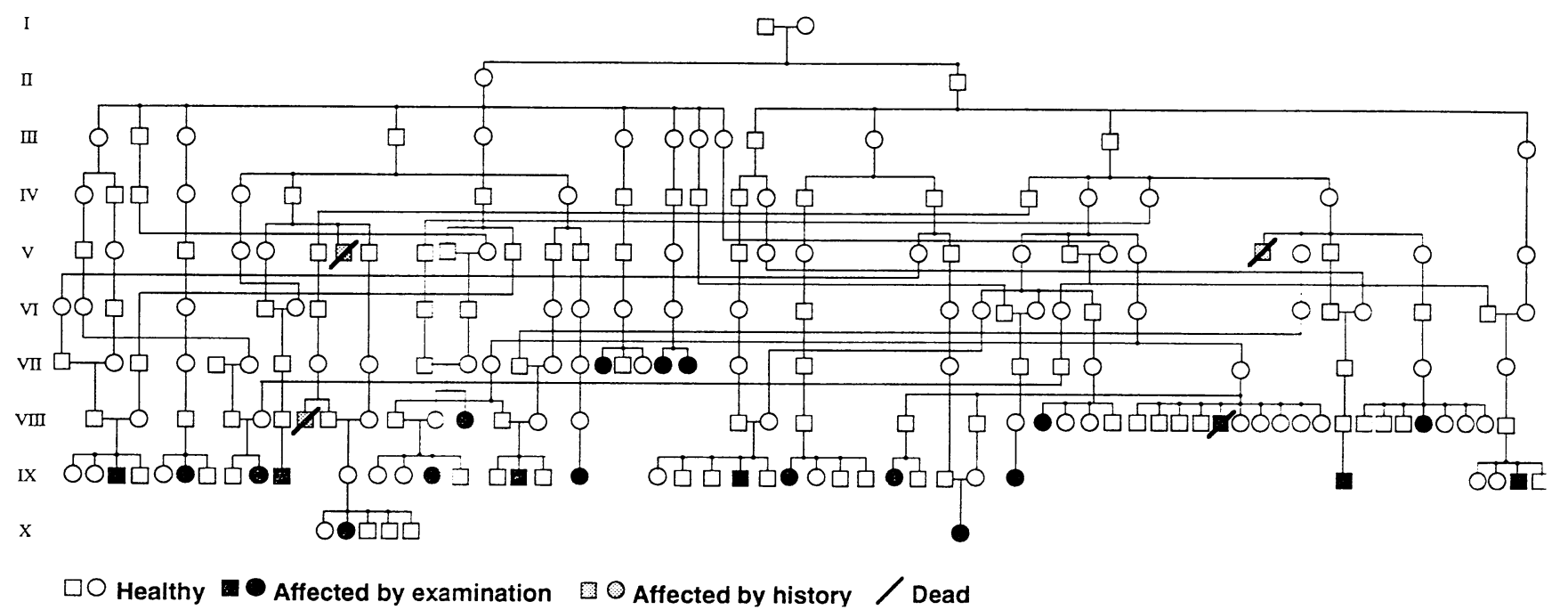

Figure 2 Pedigree of family with multiple sclerosis in northern Sweden. 
in this district. By comparison, a pedigree analysis of familial amyloidotic polyneuropathy in another county in northern Sweden showed family ties in 63 out of 127 registered patients with the disease in the region. ${ }^{14}$ The high disease prevalence in this population could of course be due to a high frequency of major exogenous risk factors, but no obvious potential environmental factor of importance could be identified. There was no clustering by year of onset as would be expected in the event of a major infectious cause Furthermore, five of the patients in the pedigree were not even born in Överkalix and most of the patients were not resident in the district at the time of onset of disease. Thus exposure to exogenous factors has not been uniform and it seems unlikely that environmental factors contribute substantially to the high occurrence of multiple sclerosis in the pedigree.

The pedigree as such does not, however, give us any exact information about the mode of inheritance but it is in agreement with previous studies that exclude simple mendelian (autosomal dominant, autosomal recessive, $x$ linked recessive) inheritance. ${ }^{15}$ Family data in these studies also rule out vertical transmission (mitochondrial or placental) and speculations about a Y-linked resistance gene or parental imprinting also seems unlikely..$^{15}$ Thus most of the family data available provide evidence for susceptibility to multiple sclerosis being polygenic. ${ }^{15-17}$ This too is certainly not contradicted by our pedigree, and the lack of solid evidence of disease in earlier generations makes it difficult to hypothesise different segregation patterns. Recently a Finnish group found linkage to myelin basic protein located on chromosome 18 in 21 families from the county of Österbotten in the western part of Finland. ${ }^{18}$ They proposed an autosomal dominant inheritance with reduced penetrance.

Linkage studies of the family described in this report should also prove to be powerful and through segregation analysis we plan to study how different markers are inherited compared with the heredity of the disease itself. Also the recognition of additional traits that segregate with multiple sclerosis would be of particular interest, as this approach has been successfully exploited for other neuro- logical diseases. Furthermore, identification of clinical phenotypes that cluster within families may delineate subgroups within the familial multiple sclerosis population.

The molecular basis for an inherited susceptibility to multiple sclerosis remains unknown but there is a strong probability that multiple sclerosis has more than one aetiology and that the genetic contribution to the disease involves more than one gene.

This work was supported by grants from the Swedish Multiple Sclerosis Society and the Karl Oskar Hansson Research Fund.

1 Myrianthopoulos NC. Genetic aspects of multiple sclerosis. In: PJ Vinken, GW Bruyn, HL Klawans and JC Koetsier, eds. Handbook of neurology. Vol 47; rev series 3. Amsterdam: Elsevier, 1985:289-317.

2 Sadovnick AD, Macleod PMJ. The familial nature of multiple sclerosis: empiric recurrence risks for first, second and third degree relatives of patients. Neurology 1981;31:1039-41.

3 Ebers GC, Bulman DE, Sadovnick AD, et al. A population-based study of multiple sclerosis in twins. $N$ Engl $\mathcal{F}$ Med 1986;315:1638-42.

4 Kinnunen E, Koskenvuo M, Kapprio J, Aho K. Multiple sclerosis in a nationwide series of twins. Neurology 1986;37:1627-9.

5 Kurtzke JF. Epidemiology of multiple sclerosis. In: Vinken PJ, Bruyn GW, Klawans HL, Koetsier JC, eds. Handbook of neurology. Vol 47; rev series 3. Amsterdam: Elsevier, 1985:259-87.

6 Deacon WE, Alexander L, Siedler HD, Kurland LT. Multiple sclerosis in a small New England community. $N$ Engl f Med 1959;261:1059-61.

7 Eastman R, Sheridan J, Poskanzer DC. Multiple sclerosis clustering in a small Massachusetts community with possible common exposure 23 years before onset. $N$ Engl $¥$ Med 1973;289:793-4.

8 Hader WI, Irvine DG, Schiefer HB. A cluster-focus of multiple sclerosis at Henribourg, Saskatchewan. Can $\mathcal{f}$ Neurol Sci 1990;17:391-4.

9 Kurtzke JF. Familial incidence and geography in multiple sclerosis. Acta Neurol Scand 1965;41:127-39.

10 Mackay RP, Myrianthopoulos NC. Multiple sclerosis in twins and their relatives. Final report. Arch Neurol 1966; 15:449-62.

11 Pratt RTC, Compston ND, McAlpine D. The familial incidence of disseminated sclerosis and its significance. Brain 1957;74:191-232.

12 Schumacher GA, Beebe GW, Kibler RF, et al. Problems of experimental trials of therapy in multiple sclerosis. Ann N Y Acad Sci 1965;122:552-68.

13 Kurtzke JF. Further notes on disability evaluation in multiple sclerosis with scale modifications. Neurology 1965;15:654-61.

14 Drugge U, Andersson R, Chizari F, et al. Familial amyloidotic polyneuropathy in Sweden: a pedigree analysis. loidotic polyneuropathy in S

15 Sadovnick AD, Bulman D, Ebers GC. Parent-child concordance in multiple sclerosis. Ann Neurol 1991;29. cordance

16 Sadnovick AD, Baird PA, Ward RH. Multiple sclerosis: updated risks for relatives. Am $\mathfrak{F}$ Med Gene 1988;29:533-41.

17 Doolittle TH, Myers RH, Lehrich JR, et al. Multiple sclerosis sibling pairs: clustered onset and familial predisposition. Neurology 1990;40:1546-52.

18 Tienari PJ, Wikström J, Sajantila A, Palo J, Peltonen L Genetic susceptibility to multiple sclerosis linked to the myelin basic protein gene. Lancet 1992;340:987-91. 